\title{
Doppler Indices and Notching Assessment of Uterine Artery Between the 19th and 22nd Week of Pregnancy in the Prediction of Pregnancy Outcome
}

\author{
DOMINIK RATIU*, KATHERINA HIDE-MOSER*, BERND MORGENSTERN, \\ INGO GOTTSCHALK, CHRISTIAN EICHLER, SEBASTIAN LUDWIG, \\ BERTHOLD GRÜTTNER, PETER MALLMANN and FABINSHY THANGARAJAH
}

Department of Obstetrics and Gynecology, University Hospital Cologne and Medical Faculty, Cologne, Germany

\begin{abstract}
Background/Aim: The aim of this study was to determine the value of Doppler indices and notching assessment of uterine artery between the 19th and 22nd week of gestation in the prediction of pregnancy outcome such as delivery mode, birth weight, Apgar score, afterbirth $\mathrm{pH}$, fetal presentation, preeclampsia and fetal growth restriction in singleton pregnancy. Patients and Methods: This is a retrospective cohort study of Doppler ultrasound of the uterine arteries at 19-22 week of gestation in 1,472 women with singleton pregnancies. Results: Patients with bilateral high resistance-index $(R I)$ and pulsatility-index $(R I)$ or with the presence of a notch showed a significantly higher prevalence of small for gestational age (SGA) fetuses and intrauterine growth restriction (IUGR), low Apgar Scores at the 1 st and the 5 th $\mathrm{min}$, high $\mathrm{c}$-section rate, preterm birth, breech birth, placental insufficiency and placental abruption. The presence of a notch significantly increased the prevalence of severe preeclampsia, HELLP-syndrome and oligohydramnios. Also, patients with a bilateral uterine notching had a higher c-section rate along with higher prevalence of SGA and IUGR at screening time. Conclusion: Uterine artery Doppler waveform analysis as well as the assessment of the presence of a notch in the second trimester can be used as a screening method to identify women who will thereafter develop a severe adverse outcome.
\end{abstract}

This article is freely accessible online.

*These Authors contributed equally to this study.

Correspondence to: Dominik Ratiu, Department of Obstetrics and Gynecology, Medical Faculty, University Hospital Cologne, Kerpener Str. 34, 50931 Cologne, Germany. Tel: +49 22147886545, Fax: +49 22147886546, e-mail: Dominik.Ratiu@uk-koeln.de

Key Words: Doppler, uterine artery, second trimester screening, preeclampsia, fetal growth restriction.
During pregnancy, the blood supply to the uterus is enhanced and both uterine arteries are dilated to their maximum to optimize the blood flow up to $500-750 \mathrm{ml} / \mathrm{min}$ around the due date. At that time, it represents approximately 10-15\% of the maternal cardiac output (1). It is in fact the result of the physiological reduction in systemic vascular resistance as well as a reduction in blood viscosity $(2,3)$. Abnormal uterine waveforms or the persistence of a diastolic notch beyond 24 weeks of gestation are associated with secondarily inadequate trophoblast invasion of the spiral arteries $(4,5)$. The inadequate uteroplacental formation has been implicated in the pathophysiology of multiple pregnancy-associated pathologies such as pre-eclampsia, intrauterine growth restriction or small for gestational age (SGA) fetuses.

A great number of Doppler studies in the last 25-30 years have confirmed the association between the increased blood flow resistance in the uterine arteries and a higher risk of the consequent development of pre-eclampsia, intrauterine growth restriction or SGA $(3,6,7)$. These conditions are still major causes for perinatal maternal and fetal morbidity and mortality and affect approximately 4-10\% of all pregnancies (3).

In this study, we tried to evaluate if the uterine artery Doppler waveform analysis as well as the assessment of the presence of a notch in the second trimester in unselected women with singleton pregnancies correlates with significant differences in common pregnancy outcomes as well as the development of several pathologies.

\section{Patients and Methods}

The Doppler ultrasound of the uterine arteries at 19-22 weeks of gestation was examined in women with singleton pregnancies. The ultrasound screening was performed in 1,472 women during a routine target scan in the Department of Obstetrics and Gynecology at the University of Cologne between January 1, 2008 and December 31, 2017.

The sonographers, three experienced gynecologists with the DEGUM II qualification, performed the examination of the Doppler 
of the uterine arteries between 19 and 22 weeks of pregnancy using a curvilinear probe. The uterine arteries are a measure of the uteroplacental flow and a branch of the anterior division of the internal iliac artery. Doppler examinations of this vessels were performed transabdominally. The probe was placed longitudinally in the lower lateral quadrant of the abdomen, angled medially and using color flow mapping to identify the uterine artery as it is seen crossing the external iliac artery. The sample volume was placed 1 $\mathrm{cm}$ downstream from this crossover point. The same process was repeated for the contralateral uterine artery (8).

A Resistance-index (RI) and pulsatility-index (PI) were calculated from each uterine artery and the presence or absence of a notch was determined. A PI or RI $>90 \%$-Interval or the presence of any diastolic notch were defined as pathological and were compared regarding multiple adverse pregnancy outcomes with the control group (9).

Statistical analysis was performed using the IBM SPSS 24 Software. The $\mathrm{Chi}^{2}$ Test and one-way ANOVA were used to compare variable outcomes in the four different patient groups (control group, pathological Doppler unilaterally, bilateral pathological Doppler, uni- and bilateral presence of a notch). A $p$ value below 0.05 was considered to be statistically significant.

\section{Results}

During a period of 10 years, 1472 women with singleton pregnancies were examined. A total of 802 (54.5\%) women had normal Doppler indices, $396(26.9 \%)$ women unilaterally abnormal PI or RI, for 151 (10.3\%) women PI or RI were pathological for both uterine arteries, for 64 (4.4\%) women the presence of a notch was unilaterally and for 59 women $(4.0 \%)$ it was observed on both sides. Patients' repartition is demonstrated in Table I. The study showed no significant differences in all four groups regarding maternal age as well as the development of placenta previa, polyhydramnios, amniotic infection syndrome, fetal death, CTG abnormalities, mild pre-eclampsia and shoulder dystocia.

There were $16(1.1 \%)$ cases of severe pre-eclampsia and $5(0.3 \%)$ cases of diagnosed HELLP syndrome. There were 46 cases of placental insufficiency, 26 cases with oligohydramnios, 203 cases with SGA and 80 with intrauterine growth restriction (10). In this study, we defined as SGA neonates with a birthweight below the 10th percentile and intrauterine grow restriction as a birthweight for gestational age below the 3rd percentile. The prevalence of placental insufficiency, oligohydramnios, SGA and intrauterine grow restriction was $3.1 \%, 1.8 \%, 13.8 \%, 5.4 \%$ respectively. Further, we observed $8(0.5 \%)$ cases of placental abruption. We were able to determine that patients with bilateral high PI or RI or the presence of a notch showed a significantly higher prevalence of SGA $(p<0.001)$ and IUGR $(p<0.001)$ at birth. Around $14.8 \%$ of the neonates born with SGA and $16.3 \%$ with IUGR presented pathological Doppler indices on both uterine arteries and 27.1\% SGA children and $41.3 \%$ with IUGR showed the presence of a notch $(p<0.001)$. We also observed that the presence of a
Table I. The study population.

\begin{tabular}{lcc}
\hline & N (1472) & $\%$ \\
\hline Normal doppler & 802 & 54.5 \\
Unilaterally abnormal PI or RI & 396 & 26.9 \\
Bilaterally abnormal PI or RI & 151 & 10.3 \\
Unilaterally notch & 64 & 4.3 \\
Bilaterally notch & 59 & 4.0 \\
\hline
\end{tabular}

bilateral notch significantly increased the risk of developing SGA $(64.4 \%$ vs. $26.6 \%$ with a unilateral notch $/ p<0.001)$ or IUGR (49.2\% vs. $6.3 \%$ with a unilateral notch, $p<0.001)$ (Table II, Figure 1).

Patients with a pathologically high PI or RI on both sides or with the presence of a notch also showed lower Apgar Score after the 1 st and the 5 th $\min (p<0.001)$. The group with a notch recovered $10 \mathrm{~min}$ after birth, whereas the group with bilateral pathological Doppler indices still presented lower Apgar scores. Concerning the Apgar Scores as well as acidosis at birth, the study revealed that patients with a unilateral notch had higher Apgar Score for all three scores $(p<0.001)$ and a higher prevalence of normal afterbirth $\mathrm{pH}(64.1 \%$ vs. $45.8 \%$ with a bilateral notch, $p=0.012$ ) compared to the patients presenting a notch on both arteries (Figures 2 and 3).

Additionally, the data analysis disclosed that the patient groups with the presence of a notch and with a bilateral PI or RI $>90 \%$-Interval had a higher rate of c-section $(65.8 \%$ and $54.3 \%$, respectively, $p=0.023$ ), preterm birth before the 32 weeks of gestation ( $26.8 \%$ and $16.6 \%$ respectively, before 28 weeks of gestation as well as $13.8 \%$ and $7.3 \%$ between $28-32$ weeks of gestation, $p<0.001)$, breech birth $(211 \%$ and $16.6 \%$, respectively, $p<0.001)$, placental insufficiency $(12.2 \%$ and $4.0 \%$, respectively, $p<0.001)$ and placental abruption $(2.4 \%$ and $1.3 \%$, respectively, $p=0.008$ ). The prevalence of SGA (respectively $26.0 \%$ and $7.9 \%, p<0.001)$ and IUGR $(17.1 \%$ and $5.3 \%$, respectively, $p<0.001$ ) at the time of screening in these patient groups was significantly superior to the prevalence in the other groups (Figures 4 and 5).

This study also showed that the presence of a notch significantly increased the prevalence of severe preeclampsia (4\% vs. $0.6-1.3 \%$ for the other patient groups, $p=0.008$ ), HELLP-syndrome (2.4\% vs. $0.0-0.2 \%$ for the other groups, $p=0.005)$ and oligohydramnios $(5.7 \%$ vs. $0.7-1.5 \%$ for the other patient groups, $p=0.004)$.

Bilateral uterine notching showed a higher prevalence to develop oligohydramnios $(6.8 \%$ vs. $4.7 \%$ with a unilateral notch, $p=0.002)$, placental abruption $(3.4 \%$ vs. $1.6 \%$ with a unilateral notch, $p=0.004)$, placental insufficiency $(23.7 \% \mathrm{vs}$. $1.6 \%$ with a unilateral notch, $p<0.001)$, severe preeclampsia (5.1\% vs. $3.1 \%$ with a unilateral notch, $p=0.002)$, HELLP 
Table II. Patients' characteristics.

\begin{tabular}{|c|c|c|c|c|c|}
\hline & $\begin{array}{l}\text { Normal } \\
\text { pregnancy }\end{array}$ & $\begin{array}{c}\text { Unilaterally } \\
\text { abnormal doppler }\end{array}$ & $\begin{array}{c}\text { Bilaterally } \\
\text { abnormal doppler }\end{array}$ & $\begin{array}{l}\text { Unilaterally } \\
\text { notch }\end{array}$ & $\begin{array}{l}\text { Bilaterally } \\
\text { notch }\end{array}$ \\
\hline Mild pre-eclampsia & $2(0.2 \%)$ & $3(0.8 \%)$ & $1(0.7 \%)$ & $0(0.0 \%)$ & $0(0.0 \%)$ \\
\hline Moderate pre-eclampsia & $2(0.2 \%)$ & $1(0.3 \%)$ & $1(0.7 \%)$ & $0(0.0 \%)$ & $0(0.0 \%)$ \\
\hline Severe pre-eclampsia & $5(0.6 \%)$ & $5(1.3 \%)$ & $1(0.7 \%)$ & $2(3.1 \%)$ & $3(5.1 \%)$ \\
\hline HELLP & $2(0.2 \%)$ & $0(0.0 \%)$ & $0(0.0 \%)$ & $0(0.0 \%)$ & $3(5.1 \%)$ \\
\hline IUGR & $15(1.9 \%)$ & $5(1.3 \%)$ & $7(4.6 \%)$ & $4(6.3 \%)$ & $8(13.6 \%)$ \\
\hline IUFT & $9(1.1 \%)$ & $5(1.3 \%)$ & $4(2.6 \%)$ & $1(1.6 \%)$ & $1(1.7 \%)$ \\
\hline CTG abnormalities & $80(10.0 \%)$ & $36(9.1 \%)$ & $8(5.3 \%)$ & $10(15.6 \%)$ & $6(10.2 \%)$ \\
\hline Amniotic infection syndrome & $13(1.6 \%)$ & $4(1.0 \%)$ & $4(2.6 \%)$ & $1(1.6 \%)$ & $0(0.0 \%)$ \\
\hline Placenta insufficiency & $13(1.6 \%)$ & $12(3.0 \%)$ & $6(4.0 \%)$ & $1(1.6 \%)$ & $14(23.7 \%)$ \\
\hline Placenta abruption & $2(0.2 \%)$ & $1(0.3 \%)$ & $2(1.3 \%)$ & $1(1.6 \%)$ & $2(3.4 \%)$ \\
\hline Placenta previa & $17(2.1 \%)$ & $9(2.3 \%)$ & $3(2.0 \%)$ & $0(0.0 \%)$ & $1(1.7 \%)$ \\
\hline Oligohydramnios & $12(1.5 \%)$ & $6(1.5 \%)$ & $1(0.7 \%)$ & $3(4.7 \%)$ & $4(6.8 \%)$ \\
\hline Polyhydramnios & $6(0.7 \%)$ & $5(1.3 \%)$ & $0(0.0 \%)$ & $3(4.7 \%)$ & $0(0.0 \%)$ \\
\hline Shoulder dystocia & $6(0.7 \%)$ & $1(0.3 \%)$ & $0(0.0 \%)$ & $1(1.6 \%)$ & $0(0.0 \%)$ \\
\hline Weight under 3 rd percentile & $24(30.0 \%)$ & $10(2.5 \%)$ & $13(8.6 \%)$ & $4(6.3 \%)$ & $29(49.2 \%)$ \\
\hline Weight under 10th percentile & $76(9.5 \%)$ & $42(10.6 \%)$ & $30(19.9 \%)$ & $17(26.6 \%)$ & $38(64.4 \%)$ \\
\hline Preacidosis & $89(11.1 \%)$ & $44(11.1 \%)$ & $16(10.6 \%)$ & $12(18.8 \%)$ & $6(10.2 \%)$ \\
\hline Mild acidosis & $38(4.7 \%)$ & $20(5.1 \%)$ & $5(3.3 \%)$ & $3(4.7 \%)$ & $8(13.6 \%)$ \\
\hline Moderate acidosis & $28(3.5 \%)$ & $10(2.5 \%)$ & $2(1.3 \%)$ & $0(0.0 \%)$ & $0(0.0 \%)$ \\
\hline Advanced acidosis & $4(0.5 \%)$ & $3(0.8 \%)$ & $4(2.6 \%)$ & $1(1.6 \%)$ & $0(0.0 \%)$ \\
\hline Severe acidosis & $0(0.0 \%)$ & $1(0.3 \%)$ & $2(1.3 \%)$ & $0(0.0 \%)$ & $0(0.0 \%)$ \\
\hline
\end{tabular}

( $5.1 \%$ vs. $0.0 \%$ with a unilateral notch, $p<0.001)$, breech birth $(32.2 \%$ vs. $10.9 \%$ with a unilateral notch, $p=0.010)$, as well as preterm birth before 32 weeks of gestation $(45.8 \%$ vs. $9.4 \%$ with a unilateral notch before 28 weeks of gestation and $16.9 \%$ vs. $10.9 \%$ with a unilateral notch between $28-32$ weeks of gestation, $p<0.001)$ compared to patients presenting an unilateral notch of the uterine arteries. The analysis also revealed that patients presenting a bilateral notching had a higher c-section rate $(78.0 \%$ vs. $54.7 \%$ with a unilateral notch, $p=0.008)$. Finally, the prevalence of SGA (42.4\% vs. $10.9 \%$ with a unilateral notch, $p<0.001)$ and IUGR $(32.2 \%$ vs. $3.1 \%$ with a unilateral notch, $p<0.001)$ at screening time was significantly superior to the prevalence in the other groups.

\section{Discussion}

The data analysis in this study indicated that abnormal uterine Doppler indices and the presence of a notch between the 19th and 22nd weeks of gestation in normal singleton pregnancies is a risk factor of developing adverse maternal and fetal outcomes such as fetal growth restriction, SGA, severe preeclampsia, HELLP, oligohydramnios placental insufficiency and placental abruption. These findings are compatible with previous studies of uterine arteries Doppler screening and the combined screening including maternal characteristics and history $(3,5,11-21)$. Although the identification of high-risk pregnancies in the second trimester could not yet improve maternal and fetal morbidity and mortality as demonstrated in several studies in the past 20 years, the administration of a daily low dose of aspirin starting before the 16th week of gestation has shown significant reduction in the prevalence of these complications $(3,11,22$ 25).

Moreover, the study revealed that women presenting a bilateral uterine notching had higher maternal and fetal morbidity compared to women presenting only a unilateral uterine notching, which corroborates numerous studies researching second trimester screening methods to improve maternal and neonatal outcomes $(5,13,26,27)$.

Indeed, the pathophysiology of uterine artery notching has not been completely examined. An explanation for the presence of uterine artery notching is still discussed and different interpretations have been proposed, such as an increased compliance of the arterial wall or uterine artery endothelial cell dysfunction $(13,28,29)$.

The major strengths of this retrospective study are the large number of pregnancy scans during routine second trimester screenings and the fact that it was conducted by experienced gynecologists with years of experience.

One of the challenges of the study is the inconsistent definition in literature of uterine growth restriction (in our study a weight under the 3rd percentile) and SGA (weight under the 10th percentile). 


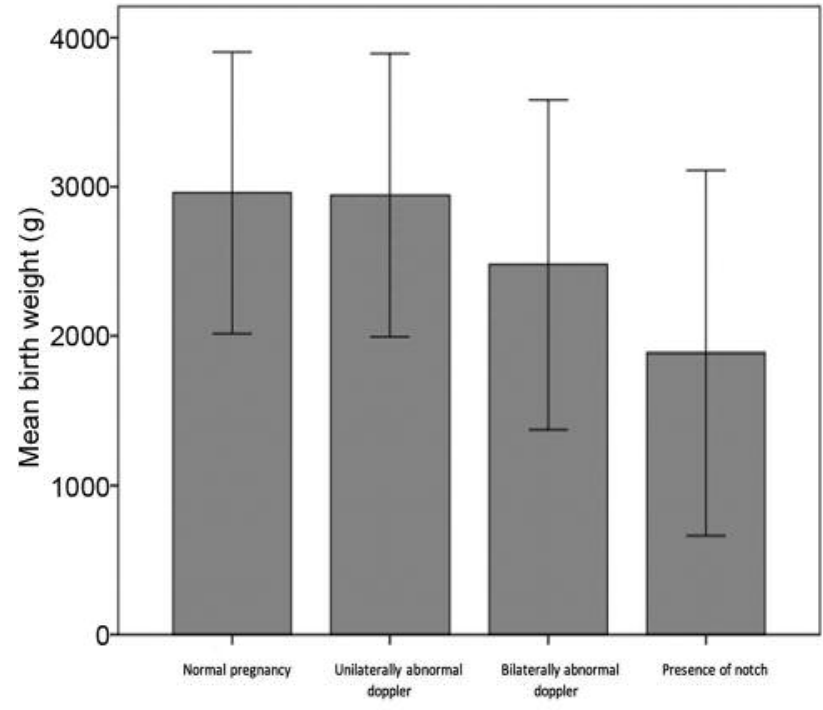

Figure 1. Graphs showing the relationship between the mean birthweight (in $\mathrm{kg}$ ) and the uterine Doppler indices or the presence of a notch.

The assessment of uterine Doppler indices as a noninvasive screening method should help us identify high-risk pregnancies and adapt the clinical management toward a more patient-specific practice (26). The identification of a high-risk group of women enables to determine the best time and place for delivery and therefore reduces maternal and fetal morbidity and mortality $(11,15,26)$. Also, a risk stratification recommending a closer monitoring of these pregnancies or an extended 1st trimester screening combining multiple maternal and fetal factors may not only permit the identification, but also the reduction of the prevalence of such adverse pregnancy outcomes $(11,12,16,19,21,23,25,30,31)$.

\section{Conclusion}

Pathological Doppler indices on both uterine arteries meaning bilateral PI or RI $>90 \%$-Interval or the presence of a notch between the 19th and 22th week of pregnancy represent a risk of developing severe adverse outcomes, such as preterm birth before 32 weeks of gestation, fetal growth restriction, severe pre-eclampsia, HELLP, oligohydramnios, placental insufficiency and placental abruption.

Moreover, the study revealed that especially patients with a bilateral notch showed a higher prevalence to develop these severe adverse outcomes. These indices should be used in the clinical practice to identify the high-risk women. They should be reevaluated during a third-trimester screening to improve monitoring and the clinical management and reduce maternal and fetal morbidity and mortality.

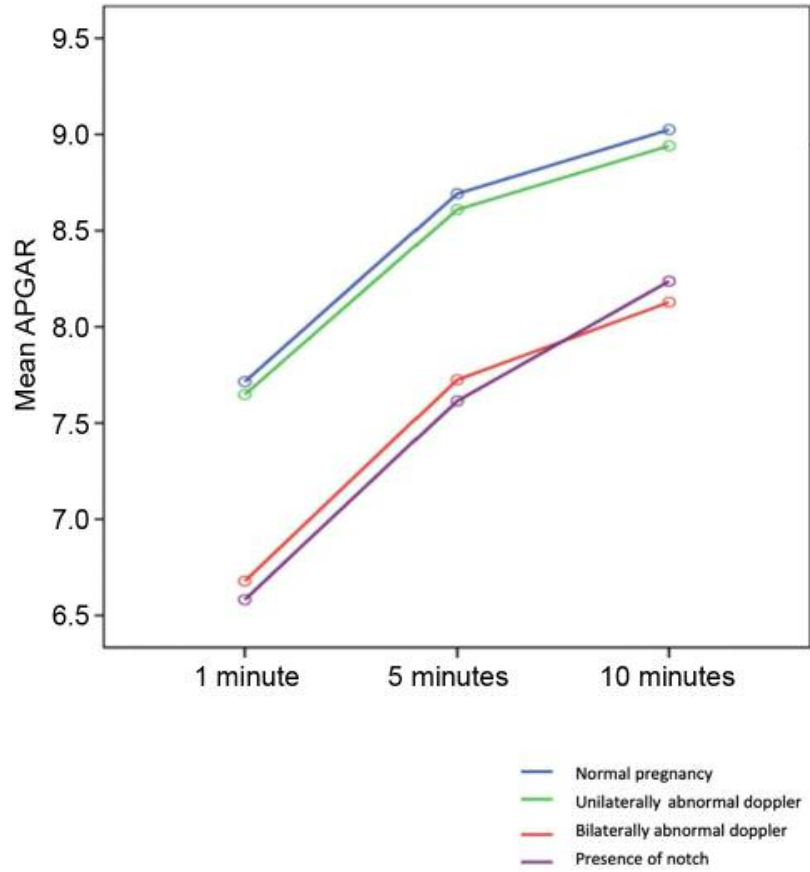

Figure 2. Graphs showing the relationship between the mean APGAR Score (after 1, 5, $10 \mathrm{~min}$ ) and the uterine Doppler indices or the presence of a notch.

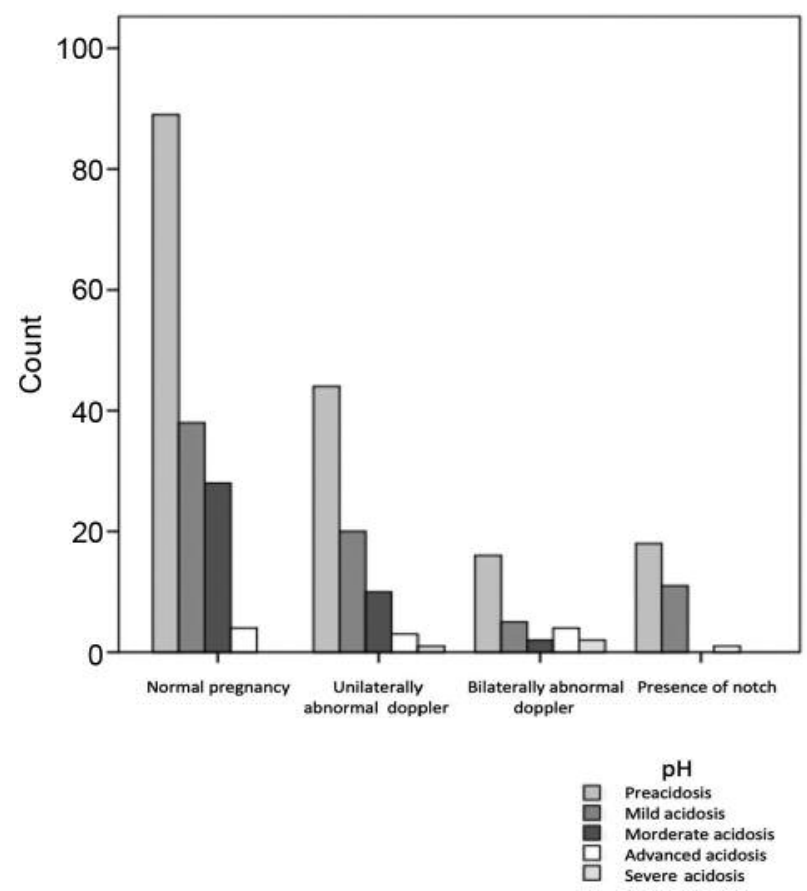

Figure 3. Graphs showing the relationship between the acidosis at birth and the uterine Doppler indices or the presence of a notch. 


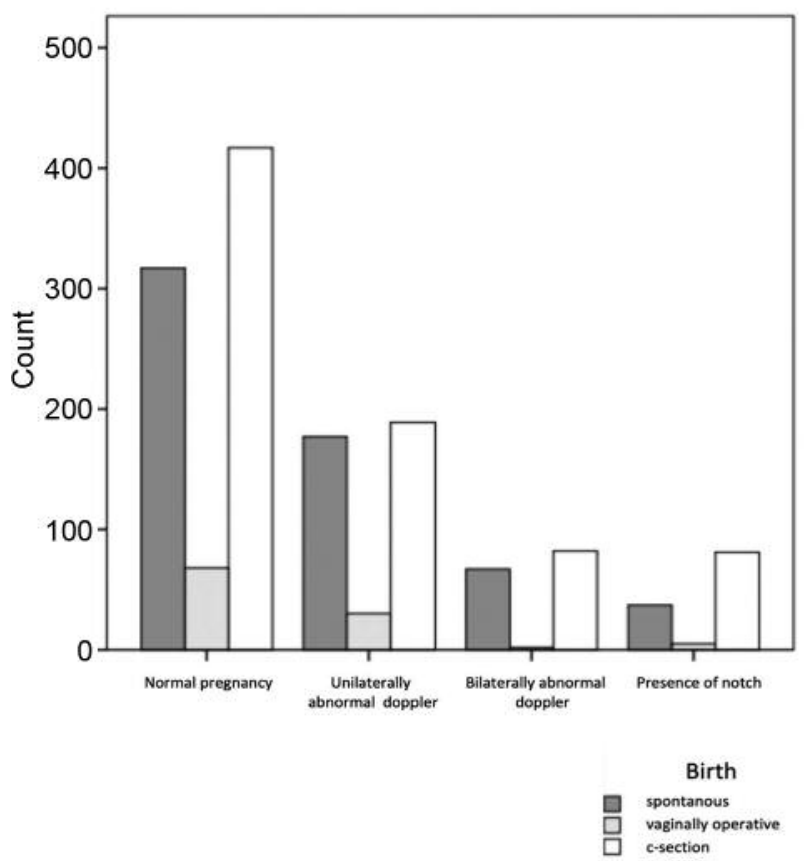

Figure 4. Graphs showing the relationship between modes of delivery and the uterine Doppler indices or the presence of a notch.

\section{Conflicts of Interest}

The Authors declare that they have no conflicts of interest regarding this study.

\section{Authors' Contributions}

DR: Project development, manuscript writing, KHM: manuscript writing, data collection, statistical analysis, BM: manuscript editing, data collection, IG: manuscript editing, data collection, CE: manuscript editing, data collection, SL: manuscript editing, data collection, PM: manuscript editing, data collection, FT: manuscript writing, data collection, project development, BG: manuscript writing, data collection, project development

\section{References}

1 Graf AH: Morphologie, Physiologie und Pathologie des maternoplazentaren, fetoplazentaren und fetalen Kreislaufs. In: Steiner H, Schneider K-TM (Hrsg.). Dopplersonographie in Geburtshilfe und Gynäkologie: Leitfaden für die Praxis. Berlin, Heidelberg: Springer Berlin Heidelberg, pp. 3-12, 2012.

2 Clapp JF and Capeless E: Cardiovascular function before, during, and after the first and subsequent pregnancies. Am J Cardiol 80: 1469-1473, 1997. PMID: 9399724. DOI: 10.1016/ s0002-9149(97)00738-8

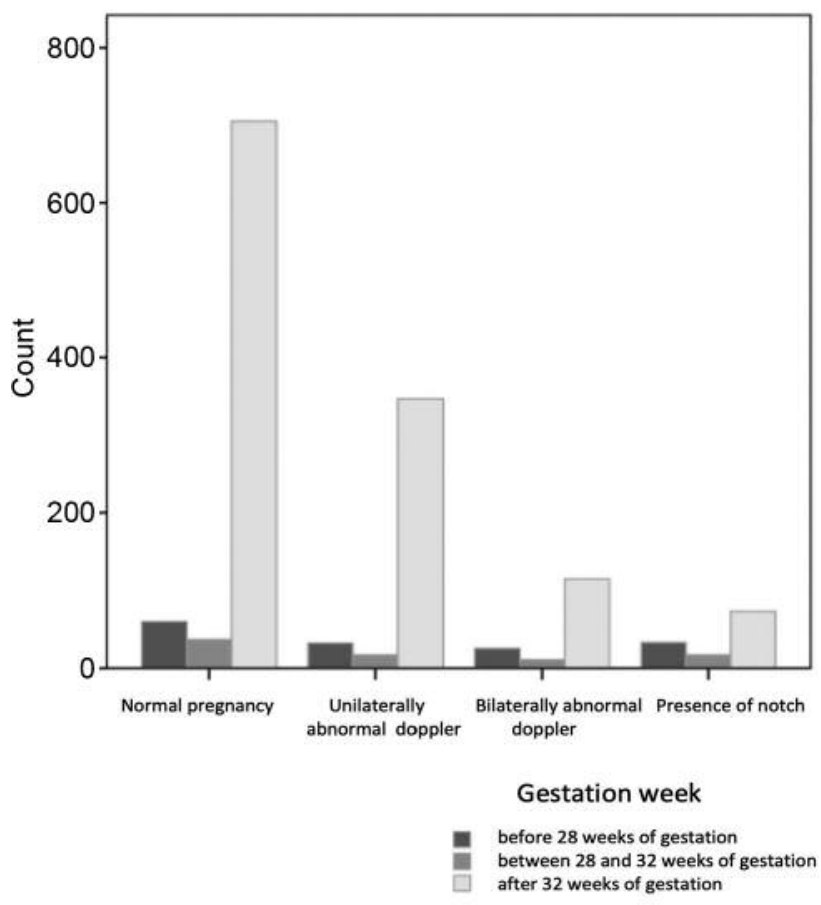

Figure 5. Graphs showing the relationship between the gestational age at delivery and the uterine Doppler indices or the presence of a notch.

3 García B, Llurba E, Valle L, Gómez-Roig MD, Juan M, PérezMatos C, Fernández M, García-Hernández JA, Alijotas-Reig J, Higueras MT, Calero I, Goya M, Pérez-Hoyos S, Carreras E and Cabero L: Do knowledge of uterine artery resistance in the second trimester and targeted surveillance improve maternal and perinatal outcome? UTOPIA study: a randomized controlled trial. Ultrasound Obstet Gynecol 47: 680-689, 2016. PMID: 26823208. DOI: 10.1002/uog.15873

4 McMaster-Fay RA: Midtrimester uterine artery Doppler studies in predicting preeclampsia. Am J Obstet Gynecol 216: 332-333, 2017. PMID: 27815061. DOI: 10.1016/j.ajog.2016.10.036

5 Cnossen JS, Morris RK, ter Riet G, Mol BWJ, van der Post JAM, Coomarasamy A, Zwinderman AH, Robson SC, Bindels PJE, Kleijnen J and Khan KS: Use of uterine artery Doppler ultrasonography to predict pre-eclampsia and intrauterine growth restriction: a systematic review and bivariable meta-analysis. CMAJ 178: 701-711, 2008. PMID: 18332385. DOI: 10.1503/ cmaj.070430

6 Papageorghiou AT, Yu CK, Bindra R, Pandis G, Nicolaides KH and Fetal Medicine Foundation Second Trimester Screening Group: Multicenter screening for pre-eclampsia and fetal growth restriction by transvaginal uterine artery Doppler at 23 weeks of gestation. Ultrasound Obstet Gynecol 18: 441-449, 2001. PMID: 11844162. DOI: 10.1046/j.0960-7692.2001.00572.x

7 Papageorghiou AT, Yu CKH and Nicolaides KH: The role of uterine artery Doppler in predicting adverse pregnancy outcome. Best Pract Res Clin Obstet Gynaecol 18: 383-396, 2004. PMID: 15183134. DOI: 10.1016/j.bpobgyn.2004.02.003 
8 Schaffer H, Jäger T and Steiner H: Technik der Blutflussmessung in der Geburtshilfe. In: Steiner H and Schneider K-TM (Hrsg.): Dopplersonographie in Geburtshilfe und Gynäkologie: Leitfaden für die Praxis. Berlin, Heidelberg: Springer Berlin Heidelberg, pp. 29-39, 2012. DOI: 10.1007/978-3-642-20938-3_4

9 Merz E: Sonographische Diagnostik in Gynäkologie und Geburtshilfe. Band 2: Geburtshilfe. Stuttgart: Thieme Verlag, 2002.

10 Voigt M, Fusch C, Olbertz D, Hartmann K, Rochow N, Renken $\mathrm{C}$ and Schneider KTM: Analyse des Neugeborenenkollektivs der Bundesrepublik Deutschland. Geburtshilfe Frauenheilkd 66: 956-970, 2006. DOI: 10.1055/s-2006-924458.

11 Gallo DM, Poon LC, Akolekar R, Syngelaki A and Nicolaides KH: Prediction of preeclampsia by uterine artery doppler at 2024 weeks' gestation. FDT 34: 241-247, 2013. PMID: 24192614. DOI: $10.1159 / 000356171$

12 Wright D, Akolekar R, Syngelaki A, Poon LCY and Nicolaides $\mathrm{KH}$ : A competing risks model in early screening for preeclampsia. FDT 32: 171-178, 2012. PMID: 22846473. DOI: $10.1159 / 000338470$

13 Espinoza J, Kusanovic JP, Bahado-Singh R, Gervasi MT, Romero R, Lee W, Vaisbuch E, Mazaki-Tovi S, Mittal P, Gotsch F, Erez O, Gomez R, Yeo L and Hassan SS: Should bilateral uterine artery notching be used in the risk assessment for preeclampsia, small-for-gestational-age, and gestational hypertension. J Ultrasound Med 29: 1103-1115, 2010. PMID: 20587434. DOI: 10.7863 jum.2010.29.7.1103

14 Abdel Razik M, Mostafa A, Taha S and Salah A: Combined Doppler ultrasound and platelet indices for prediction of preeclampsia in high-risk pregnancies. J Matern Fetal Neonatal Med 1-5, 2018. PMID: 29804487. DOI: 10.1080/14767 058.2018 .1481953

15 Lesmes C, Gallo DM, Saiid Y, Poon LC and Nicolaides KH: Prediction of small-for-gestational-age neonates: screening by uterine artery Doppler and mean arterial pressure at 19-24 weeks. Ultrasound Obstet Gynecol 46: 332-340, 2015. PMID: 25810352. DOI: $10.1002 / \operatorname{uog} .14855$

16 Akolekar R, Syngelaki A, Poon L, Wright D and Nicolaides KH: Competing risks model in early screening for preeclampsia by biophysical and biochemical markers. FDT 33: 8-15, 2013. PMID: 22906914. DOI: 10.1159/000341264

$17 \mathrm{Yu} \mathrm{CKH}$, Khouri O, Onwudiwe N, Spiliopoulos Y and Nicolaides KH: Prediction of pre-eclampsia by uterine artery Doppler imaging: relationship to gestational age at delivery and small-for-gestational age. Ultrasound Obstet Gynecol 31: 310313, 2008. PMID: 18241089. DOI: 10.1002/uog.5252

18 Lai J, Poon LCY, Pinas A, Bakalis S and Nicolaides KH: Uterine artery doppler at 30-33 weeks' gestation in the prediction of preeclampsia. FDT 33: 156-163, 2013. PMID: 23445882.

19 Pedrosa AC and Matias A: Screening for pre-eclampsia: a systematic review of tests combining uterine artery Doppler with other markers. J Perinat Med 39: 619-635, 2011. PMID: 21848482. DOI: 10.1515/JPM.2011.077

20 Papageorghiou AT, Yu CKH, Cicero S, Bower S and Nicolaides $\mathrm{KH}$ : Second-trimester uterine artery Doppler screening in unselected populations: a review. J Matern Fetal Neonatal Med 12: 78-88, 2002. PMID: 12420836. DOI: 10.1080/jmf.12.2.78.88

21 Crovetto F, Figueras F, Triunfo S, Crispi F, Rodriguez-Sureda V, Dominguez C, Llurba E and Gratacós E: First trimester screening for early and late preeclampsia based on maternal characteristics, biophysical parameters, and angiogenic factors. Prenat Diagn 35: 183-191, 2015. PMID: 25346181. DOI: 10.1002/pd.4519

22 Coleman MA, McCowan LM and North RA: Mid-trimester uterine artery Doppler screening as a predictor of adverse pregnancy outcome in high-risk women. Ultrasound Obstet Gynecol 15: 7-12, 2000. PMID: 10776006. DOI: 10.1046/j.14690705.2000.00014.x

23 Bujold E, Roberge S, Lacasse Y, Bureau M, Audibert F, Marcoux $\mathrm{S}$, Forest JC and Giguère Y: Prevention of preeclampsia and intrauterine growth restriction with aspirin started in early pregnancy: A meta-analysis. Obstet Gynecol 116: 402, 2010. PMID: 20664402. DOI: 10.1097/AOG.0b013e3181e9322a

24 Roberge S, Villa P, Nicolaides K, Giguère Y, Vainio M, Bakthi A, Ebrashy A and Bujold E: Early Administration of low-dose aspirin for the prevention of preterm and term preeclampsia: a systematic review and meta-analysis. FDT 31: 141-146, 2012. PMID: 22441437. DOI: 10.1159/000336662

25 Roberge S, Nicolaides KH, Demers S, Villa P and Bujold E: Prevention of perinatal death and adverse perinatal outcome using low-dose aspirin: a meta-analysis. Ultrasound Obstet Gynecol 41: 491-499, 2013. PMID: 23362106. DOI: 10.1002/uog.12421

26 Schneider KTM: Integration der Dopplersonographie in das klinische Management. In: Steiner H, Schneider K-TM (Hrsg.). Dopplersonographie in Geburtshilfe und Gynäkologie: Leitfaden für die Praxis. Berlin, Heidelberg: Springer Berlin Heidelberg, pp. 203-214, 2012. DOI: 10.1007/978-3-642-20938-3_19

27 von Kaisenberg CS and Steiner H: Plazentationsstörungen und feto-maternale Erkrankungen. In: Steiner H, Schneider K-TM (Hrsg.). Dopplersonographie in Geburtshilfe und Gynäkologie: Leitfaden für die Praxis. Berlin, Heidelberg: Springer Berlin Heidelberg, pp. 89-103, 2012. DOI: 10.1007/978-3-642-209383_9

28 Talbert DG: Uterine flow velocity waveform shape as an indicator of maternal and placental development failure mechanisms: a model-based synthesizing approach. Ultrasound Obstet Gynecol 6: 261-271, 1995. PMID: 8590189. DOI: 10.1046/j.1469-0705.1995.06040261.x

29 Brodszki J, Länne T, Stale H akan, Batra S and Maršál K: Altered vascular function in healthy normotensive pregnant women with bilateral uterine artery notches. BJOG 109: 546-552, 2002. PMID: 12066945. DOI: 10.1111/j.1471-0528.2002.01315.x

30 Crispi F, Llurba E, Domínguez C, Martín-Gallán P, Cabero L and Gratacós E: Predictive value of angiogenic factors and uterine artery Doppler for early-versus late-onset pre-eclampsia and intrauterine growth restriction. Ultrasound Obstet Gynecol 31: 303-309, 2008. PMID: 18058842. DOI: 10.1002/uog.5184

31 Poon LCY, Kametas NA, Maiz N, Akolekar R and Nicolaides KH: First-trimester prediction of hypertensive disorders in pregnancy. Hypertension 53: 812-818, 2009. PMID: 19273739. DOI: $10.1161 /$ HYPERTENSIONAHA.108.127977
Received August 12, 2019

Revised September 16, 2019

Accepted September 17, 2019 